This study was supported in part by the Doron Foundation, Tel Aviv.

1 Barker DJP, Winter PD, Osmond C, Margetts B, Simmonds SJ. Weight in infancy and death from ischaemic heart disease. Lancet 1989;ii:577-80

2 Barker DJP, Osmond C, Law CM. The intrauterine and early postnatal origin of cardiovascular disease and chronic bronchitis. $f$ Epidemiol Community Health 1989;43:237-40.

3 Simpson A, Mortimer JG, Silva PA, Spears G, Williams S. In: Onesti G, Kim $\mathrm{KE}$, eds. Hypertension in the young and old. New York: Grune and Stratton, 1981:154-63.

4 Cater J, Gill M. The follow-up study: medical aspects. In: Illsley R, Mitchell $\mathrm{RG}$, eds. Low birth weight, a medical, psychological and social study. RG, eds. Low birth weight, a medical,
Chichester: John Wiley, 1984:191-205.

5 Ounsted MK, Cockburn JM, Moar VA, Redman CWG. Factors associated with the blood pressures of children born to women who were hypertensive during pregnancy. Arch Dis Child 1985;60:631-5.

6 Gennser G, Rymark P, Isberg PE. Low birth weight and risk of high blood pressure in adulthood. $B M \mathcal{J}$ 1988;296: 1498-500.

7 Barker DJP, Osmond C, Golding J, Kuh D, Wadsworth MEJ. Growth in utero, blood pressure in childhood and adult life, and mortality from cardiovascular disease. BMF 1989;298:564-7.

8 Barker DJP, Bull AR, Osmond C, Simmonds SJ. Fetal and placental size and risk of hypertension in adult life. BMF 1990;301:259-62.

9 Higgings M, Keller J, Moore F, Ostrander L, Metzner H, Stock L. Studies of blood pressure in Tecumseh, Michigan. I. Blood pressure in young people and its relationship to personal and familial characteristics and complications of pregnancy in mothers. Am $\mathcal{F}$ Epidemiol 1980;111:142-55.

10 Hack M, Weissman B, Fanaroff A. Blood pressure during childhood. Comparison of very low birth weight children to normal birth weight controls [Abstract]. Pediatr Res 1990;27:93A.

11 Davies AM, Prywes R, Tzur B, Weiskopf D, Sterk VV. The Jerusalem perinatal study. 1. Design and organization of a continuing, communitybased, record-linked survey. Is f Med Sci 1969;5: 1095-101.

12 Harlap S, Davies AM, Grover NB, Prywes R. The Jerusalem perinatal study: the first decade 1964-1973. Is J Med Sci 1977;13:1073-82.

13 Kark JD, Kedem R, Revach M. Medical examination of Israeli 17-year-olds before military service as a national resource for health information. Isr J Med Sci 1986:122:318-25.

14 SAS Institute. SAS users' guide. Version 5. Cary, North Carolina: SAS Institute, 1985

15 Wilson SL, Gaffney FA, Laird WP, Fixler DE. Body size, composition, and fitness in adolescents with elevated blood pressures. Hypertension 1985;7: 417-22.

16 Lauer RM, Clarke WR. Childhood risk factors for high adult blood pressure: The Muscatine study. Pediatrics 1984;84:633-41.

17 Elford J, Phillips A, Thomson AG, Shaper AG. Migration and geographic variations in blood pressure in Britain. BMF 1990;300:291-5.

\title{
Neonatal screening strategy for cystic fibrosis using immunoreactive trypsinogen and direct gene analysis
}

Department of Chemical Pathology, Adelaide Children's Hospital, North Adelaide, South Australia 5006, Australia

Enzo Ranieri, BSC, chemist in charge, screening laboratory Richard G Ryall, PHD, head clinical chemist

C Phillip Morris, PHD, chemist in charge, molecular biology

Paul V Nelson, BSC, senior hospital scientist, special diagnostics laboratory William F Carey, PHD, chemist in charge, special diagnostics laboratory Evelyn R Robertson, FRACP, deputy director

Anthony C Pollard,

FRCPATH, director

Correspondence to: Dr Ryall.

$B M \mathcal{F}$ 1991;302:1237-40

\section{Enzo Ranieri, Richard G Ryall, C Phillip Morris, Paul V Nelson, William F Carey,}

Anthony C Pollard, Evelyn F Robertson

\section{Abstract}

Objective-To assess the effectiveness of a two tier neonatal screening strategy for cystic fibrosis, which combines estimation of immunoreactive trypsinogen followed by direct gene analysis in dried blood spot samples collected at age 5 days.

Design-Prospective study of two tier screening strategy. The first tier of testing immunoreactive trypsinogen concentration was measured in dried blood spot samples from neonates aged 4-5 days. In the second tier direct gene analysis to detect cystic fibrosis mutations $\Delta$ F508 and $\Delta I 506$ was performed in those blood spot samples which produced the highest $1 \%$ of immunoreactive trypsinogen values. Direct gene analysis was also performed on blood spot samples from infants with suspected or confirmed meconium ileus, regardless of the immunoreactive trypsinogen value.

Setting-The South Australian Neonatal Screening Programme, operating from the department of chemical pathology at Adelaide Children's Hospital.

Subjects-All 12056 neonates born in South Australia between December 1989 and June 1990. No selection criteria were applied.

Interventions-All infants found to have two recognised cystic fibrosis mutations on direct gene analysis were referred directly for clinical management, and those with one recognised cystic fibrosis mutation were recalled for a sweat test; their families were given genetic counselling.

Main outcome measures-Diagnosis or exclusion of cystic fibrosis by sweat testing of neonates identified as being at high risk of cystic fibrosis on screening and of those at minimum risk but whose subsequent clinical history raised suspicion about the disease.

Results-Of the 12056 infants screened, 11907 $(\mathbf{9 8 . 8 \% )}$ ) were reported as "cystic fibrosis not indicated" on the basis of low immunoreactive trypsinogen values. Of the $148(1 \cdot 23 \%)$ infants with raised immunoreactive trypsinogen values and one $(0.008 \%)$ with meconium ileus, $132(1.09 \%)$ were reported as cystic fibrosis not indicated, four $(\mathbf{0} \cdot 033 \%)$ were identified as having cystic fibrosis, and $13(0 \cdot 108 \%)$ were recalled for sweat testing after direct gene analysis for the presence of the $\Delta F 508$ and $\Delta I 506$ cystic fibrosis mutations. No cases of affected infants are known to have been missed to date.

Conclusion-The strategy of measurement of immunoreactive trypsinogen followed by direct gene analysis is a highly specific neonatal screen for cystic fibrosis, requiring only 2.8 families to be contacted for every case of cystic fibrosis diagnosed.

\section{Introduction}

Measurement of immunoreactive trypsinogen concentration in dried blood spot specimens taken at 4-5 days of age ${ }^{12}$ has become the preferred primary neonatal screen for cystic fibrosis. However, some unaffected infants have raised immunoreactive trypsinogen values in the neonatal period, and an unacceptable lack of specificity exists in this initial measurement. ${ }^{3}$ A screening strategy was consequently adopted $^{4}$ whereby all those infants with high values on initial blood spot testing are recalled for testing of a second blood spot specimen taken at age 4-6 weeks. ${ }^{4}$ If the second immunoreactive trypsinogen value remains high the infant is again recalled, this time for a sweat test. ${ }^{5-7}$ Such a strategy eventually reduces the false positive rate of the immunoreactive trypsinogen screen to an acceptable level, but in the intervening two to four weeks considerable anxiety is created for an appreciable number of families. Various authors have also reported affected infants who had normal immunoreactive trypsinogen concentrations on testing of the initial ${ }^{57.9}$ and second ${ }^{10}$ blood spot samples. This has resulted in uncertainty about the decision values to be applied to neonatal immunoreactive trypsinogen concentrations in blood spots in order to include most affected infants in the screen."

Before neonatal screening for cystic fibrosis is unreservedly accepted a strategy of greater specificity and sensitivity is required. ${ }^{12}$ To this end, interest has been shown in the use of direct gene analysis now that some of the mutations resulting in cystic fibrosis have been described. ${ }^{1314} \mathrm{~A}$ disadvantage of direct gene 
analysis for screening is that there are too many cystic fibrosis mutations to be included in a cost effective screen. The initial estimation of immunoreactive trypsinogen concentration must therefore remain the initial screening criterion, with specificity and sensitivity being achieved by subsequent testing for the most common cystic fibrosis mutations in selected subjects.

A successful neonatal screen for cystic fibrosis on this basis has been operating in South Australia since December 1989. The results of the first six months of this programme reported here are the first to show the practical viability of the proposed strategy and its advantages over those used previously.

\section{Materials and methods}

Blood spot specimens-Specimens to be screened were dried blood spots (Guthrie cards) routinely collected as part of a wider programme of screening 5 day old neonates for hypothyroidism, galactosaemia, and phenylketonuria in South Australia and Tasmania. Apart from standard identification and birth weight data, the presence or suspicion of meconium ileus in any infant is additional information required by the screening laboratory.

Estimation of immunoreactive trypsinogen-Discs of $3 \mathrm{~mm}$ diameter were punched from the dried blood spot specimens and assayed for immunoreactive trypsinogen concentration with a commercial enzyme immunometric assay (Neoscreen EIA, AGEN Biomedical, Queensland, Australia) modified to use europium time resolved fluorescence quantitation

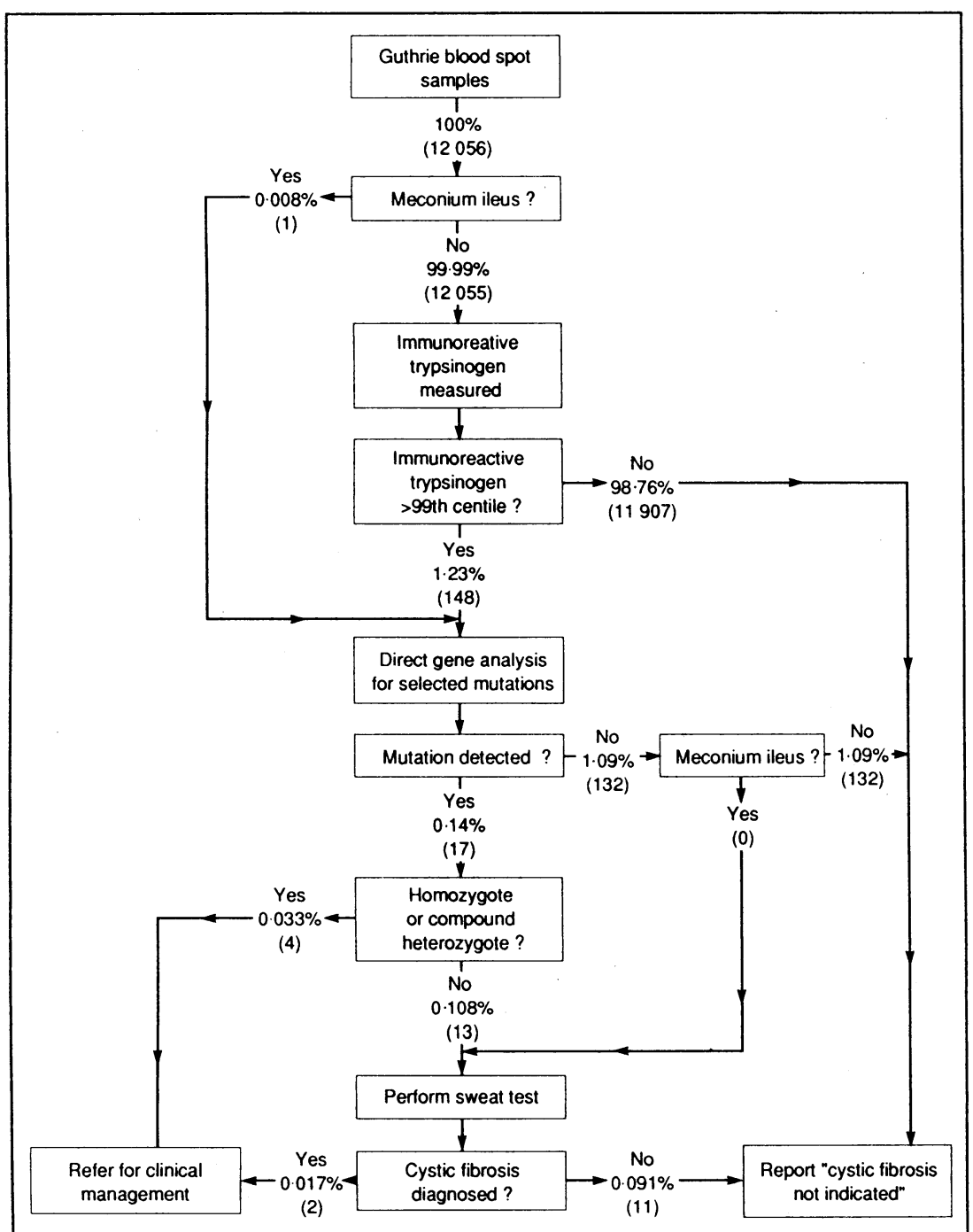

FIG 1-Neonatal screening strategy for cystic fibrosis in South Australia, showing the proportions of the population screened at each step (numbers in parentheses)
(DELFIA system, Pharmacia (Australia) Sydney, New South Wales, Australia). The change of immunoassay label from enzyme to europium significantly improved the interassay precision to a coefficient of variation of $7 \cdot 2 \%$ around the decision value $(78 \mu \mathrm{g}$ trypsin/l whole blood), resulting in less variability in the upper centiles of the population distribution of neonatal immunoreactive trypsinogen values.

Direct gene analysis-Discs of $3 \mathrm{~mm}$ diameter punched from the dried blood spot samples were placed directly into polymerase chain reaction buffer at $4^{\circ} \mathrm{C}$ and left overnight. Amplification of DNA and detection of cystic fibrosis alleles were performed according to published techniques. ${ }^{1315}$

Sweat testing-Sweat testing of infants was performed using pilocarpine iontophoresis, as originally described. ${ }^{16}$

Screening strategy-Figure 1 shows the neonatal screening strategy for cystic fibrosis. An immunoreactive trypsinogen concentration of $78 \mu \mathrm{g}$ trypsin/1 whole blood (equal to the 99th centile for the unpartitioned neonatal population) was selected as the decision value. At or above this value direct gene analysis is performed on the blood spot sample. Only two cystic fibrosis mutations were sought-namely, the $\Delta \mathrm{F} 508$ and $\Delta \mathrm{I} 506$ mutations. The prevalences of these mutations are about $72 \%$ and $1 \%$ respectively in all chromosomes carrying cystic fibrosis mutations in the general population of Australia, ${ }^{15}$ so that $93 \%$ of patients with cystic fibrosis have at least one of these mutations. Results are available within one week of receipt of the specimen. Neonates found to be homozygous for either the $\Delta \mathrm{F} 508$ or the $\Delta \mathrm{I} 506$ mutation, or a compound heterozygote of both mutations are referred directly for clinical management, which includes genetic counselling of their families. A confirmatory sweat test is performed later. When only one cystic fibrosis mutation is detected a sweat test is recommended to exclude a diagnosis of cystic fibrosis. This is performed by the age of 5 weeks. The families of those infants who carry one of the sought cystic fibrosis mutations but whose sweat test result is normal are also offered genetic counselling. Specimens from neonates in whom meconium ileus is queried or confirmed are subjected to direct gene analysis regardless of the result of immunoreactive trypsinogen testing. If no cystic fibrosis mutation is detected the infant is still recalled for a sweat test. The objective is to produce a definitive result.

\section{Results}

Figure 2 shows the distribution of immunoreactive trypsinogen concentrations obtained by the time resolved fluorescence immunometric method for the neonatal South Australian population screened, and the values in those neonates with cystic fibrosis diagnosed to date. Results from 12056 blood spot samples analysed during the first six months of screening produced 11907 samples $(98 \cdot 76 \%)$ with immunoreactive trypsinogen concentrations $<78 \mu \mathrm{g}$ trypsin/l whole blood, 148 samples $(1 \cdot 23 \%)$ with values $\geqslant 78 \mu \mathrm{g}$ trypsin/l whole blood, and one sample $(0.008 \%)$ from an infant with meconium ileus. The immunoreactive trypsinogen concentration for this last sample was $38 \mu \mathrm{g}$ trypsin/l whole blood, which is on the $78 \cdot 6$ th centile for the population.

Of the $149(1 \cdot 24 \%)$ samples selected for direct gene analysis, $132(1.09 \%)$ had neither the $\Delta F 508$ nor the $\Delta \mathrm{I} 506$ cystic fibrosis mutation, and were reported as "cystic fibrosis not indicated," along with the 11907 samples $(98 \cdot 76 \%)$ with lower immunoreactive trypsinogen values. Four samples $(0.033 \%)$ were from neonates homozygous for $\Delta \mathrm{F} 508$ who were referred directly for management of cystic fibrosis, one 


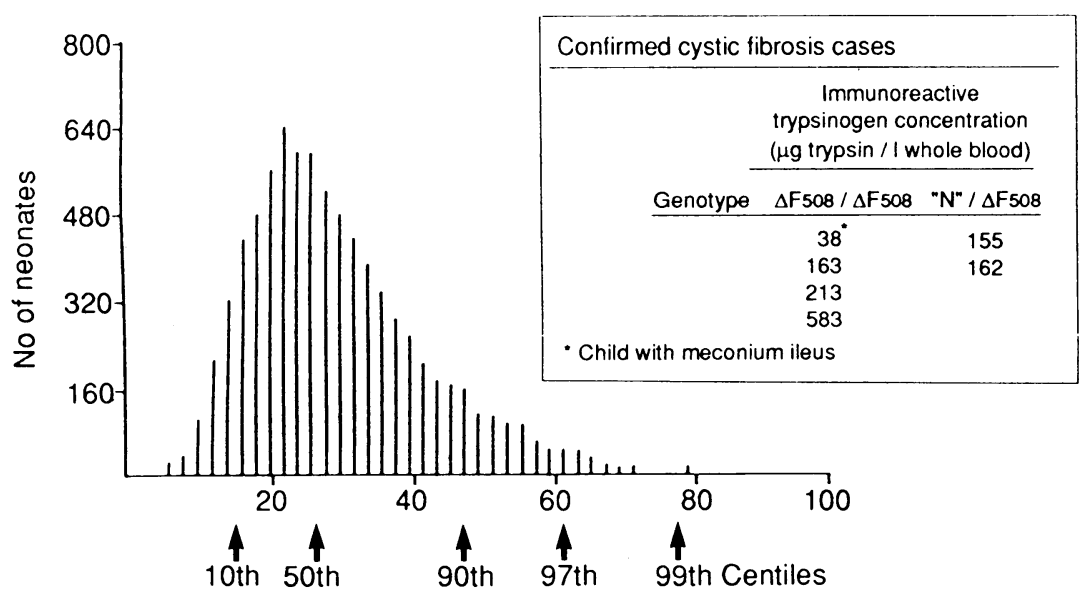

$\mu \mathrm{g}$ trypsin / I whole blood

FIG 2-Immunoreactive trypsinogen concentrations in dried blood spot $=$ specimens from 5 day old screened neonates. Decision value is $78 \mu \mathrm{g} / \mathrm{l}$ whole blood (99th centile) without meconium ileus. Values for infants with a diagnosis of cystic fibrosis are shown

of whom had meconium ileus at birth. Thirteen infants $(0 \cdot 108 \%)$ were heterozygous for $\Delta \mathrm{F} 508$ and were recalled for sweat testing, the results of which were available by the age of $4-5$ weeks. In two $(0.017 \%)$ of these infants cystic fibrosis was diagnosed on sweat testing, and they were referred for clinical management. Further investigations from the initial blood spot specimens excluded the cystic fibrosis mutations G542X, G551D, and R553X ${ }^{14}$ in these infants. The families of the remaining $11(0.091 \%)$ unaffected infants heterozygous for $\Delta \mathrm{F} 508$ were also offered further counselling and gene analysis. In every case this offer was accepted without reluctance, and each couple was able to be advised of the risks to any future pregnancy.

The incidence of cystic fibrosis detected by this strategy to date is 1:2009 liveborn children. False negative results so far are unknown with complete certainty, but the observed detection rate compares well with the known population incidence of cystic fibrosis in South Australia (1:2200 live births). The specificity of the screening strategy is $35 \cdot 3 \%$, with $2 \cdot 8$ families being contacted for every case of cystic fibrosis detected. All families contacted carry at least one cystic fibrosis mutation.

\section{Discussion}

The advantages of neonatal screening and early diagnosis of cystic fibrosis to the longer term welfare of those affected are gradually becoming evident. ${ }^{17-19} \mathrm{~A}$ practical screening strategy of higher specificity and sensitivity than has so far been published is required before such screening is unreservedly accepted. ${ }^{12}$ Two problems prohibited the implementation of currently published screening strategies in South Australia. Ethical objections were raised about collecting blood spot samples from healthy 4-6 week old infants to determine a reference range for immunoreactive trypsinogen concentration at that age. Without such data the decision of what constitutes a high immunoreactive trypsinogen concentration at this age cannot be made. ${ }^{1011}$ It was also thought unacceptable to raise the question of the presence of an incurable disease in an apparently healthy neonate without there being a strong likelihood for a positive diagnosis. The two tier screening strategy for cystic fibrosis shown in figure 1 was therefore designed to reduce the initial high false positive rate of those screens which are based solely on estimations of immunoreactive trypsinogen concentration. ${ }^{5-11}$ In this new strategy the combination of a high immunoreactive trypsinogen concentration and the presence of a recognised cystic fibrosis mutation in the initially donated blood spot specimen is the criterion on which famiies are recalled for further investigation.

This strategy achieved its aim of eliminating many false-positive results arising from the measurement of immunoreactive trypsinogen concentration in the initial blood spot. Of the screened population of 12056 neonates, 99.85\% (12039) were reported as "cystic fibrosis not indicated" because the immunoreactive trypsinogen values were less than the decision value or because neither of the cystic fibrosis mutations sought were detected. A further $\mathbf{0 . 0 3 3 \%}$ of specimens (four) led directly to a diagnosis of cystic fibrosis because of the presence of two cystic fibrosis mutations. Fewer than $0 \cdot 11 \%(13)$ of the screened neonates were recalled for sweat testing. For this last group there was a 1 in 6.5 chance of a diagnosis of cystic fibrosis. Overall, $2 \cdot 8$ families were contacted for each case of cystic fibrosis detected. These results compare favourably with those from strategies based on measurement of immunoreactive trypsinogen concentration alone. ${ }^{5.920}$ In addition, the recalled families whose infants were found subsequently not to have cystic fibrosis were alerted to the fact that at least one parent carries a cystic fibrosis mutation. Counselling included discussion about the investigation of both parents for the presence of recognised cystic fibrosis mutations to define the risks to future pregnancies. In all cases this counselling and subsequent gene analysis was accepted keenly by the families, and any residual anxiety remaining from the screening strategy was thereby removed.

Two possible sources of false negative results exist in this strategy. Various authors report false negative results by initial immunoreactive trypsinogen assay, ${ }^{5711}$ amounting to around $3 \cdot 8 \%$ of confirmed cases. ${ }^{3} \mathrm{~A}$ high analytical imprecision of about $15 \%$ coefficient of variation $^{2571021}$ around the decision value may contribute appreciably to this. With this level of analytical imprecision proposed recall rates between $0 \cdot 18 \%$ and $0.8 \%$ of neonates ${ }^{3}$ are indistinguishable from each other. In this programme the advantages of time resolved fluorescence immunoassay ${ }^{22}$ were used to improve the precision of the estimation of immunoreactive trypsinogen concentration.

Direct gene analysis imparts a greatly increased specificity to the screening strategy. Samples from those infants in whom there is clinical suspicion of meconium ileus are taken to direct gene analysis. This removes a major source of false negative results from the immunoreactive trypsinogen screen. There is, however, a priori, a 1 in 14 probability of an individual having cystic fibrosis who has neither the $\Delta F 508$ nor the $\Delta \mathrm{I} 506$ mutation. Inclusion of other cystic fibrosis mutations in the screening strategy will reduce this probability. To this end we have recently added the mutations G542X, G551D, and R553X $\mathrm{X}^{1423}$ to the screening programme. However, this source of false negative results is unlikely ever to be completely resolved. In addition, we have found that the frequency of the $\Delta F 508$ mutation in unaffected infants with high immunoreactive trypsinogen concentrations on blood spot testing is possibly skewed. About one $\Delta F 508$ mutation in every 16 samples with the highest $1 \%$ of immunoreactive trypsinogen results $(11 / 180)$ was found, compared with the expected incidence of 1 in 35 for the general population.

Financially, we found that the cost of materials for direct gene analysis of a blood spot sample is about three times that of performing an immunoreactive trypsinogen assay, with little difference in labour costs. Offset against this additional expenditure are the savings in administrative and clerical costs resulting from recalling fewer infants for further investigations $(0 \cdot 11 \% v 0 \cdot 8 \%)$, together with the intangible savings in inconvenience and anxiety for those families no longer 
recalled unnecessarily. The coincidence between the detection rate of this neonatal screening strategy and the known population incidence of cystic fibrosis is encouraging. To date the strategy has shown a high specificity and sensitivity of screening for cystic fibrosis from analysis of the initially donated blood spot specimen and is highly acceptable to the paediatricians and families using the service. The accurate screening of neonates for cystic fibrosis is consequently closer to being a reality.

1 Crossley JP, Elliot RP, Smith PA. Dried blood spot screening for cystic fibrosis in the newborn. Lancet 1979;ii:472-4.

2 King DN, Heeley AF, Walsh MP, Kuzemko JA. Sensitive trypsin assay for dried blood spot specimens as a screening procedure for early detection of cystic fibrosis. Lancet 1979;ii:1217-9.

3 Hammond K, Naylor E, Wilken B. Screening for cystic fibrosis. In: Therrell $\mathrm{BL}$, ed. Advances in neonatal screening. Amsterdam: Elsevier Science BL, ed. Advances in
Publishers 1987:377-82.

4 Adriaenssens $K$, Janssen $H$, Van Soom $H$. Two tier screen for cystic fibrosis. Lancet 1981;i:833.

5 Wilken B, Brown ARD, Urwin R, Brown DA. Cystic fibrosis screening by dried blood spot trypsin assay: results in 75000 newborn infants. F Pediat dried blood spot

6 Cassio A, Bernardi F, Piazzi S, et al. Neonatal screening for cystic fibrosis by dried blood spot trypsin assay. Acta Paediatr Scand 1984;73:554-8.

7 Ryley HC, Deam SM, Williams J, et al. Neonatal screening for cystic fibrosis in Wales and the West Midlands: 1 . Evaluation of immunoreactive trypsin test. f Clin Pathol 1988;41:726-9.

8 Heeley AF, Heeley ME, King DN, Kuzemko JA, Walch ASP. Screening for cystic fibrosis by dried blood spot trypsin assay. Arch Dis Child 1982;57: 18-21.

9 Wesley AW, Smith PA, Elliott RB. Experience with neonatal screening for cystic fibrosis in New Zealand using measurement of immunoreactive trypsinogen. Aust Paediatr 7 1989:25:151-5.

10 Rock MJ, Mischler EH, Farrell PM, et al. Newborn screening for cystic fibrosis is complicated by age-related decline in immunoreactive trypsinogen levels. Pediatrics 1990;85:1001-7.

11 Pederzini F, Mastella G, Rizzotti P, Zanchetta M. Serum lipase and trypsin in neonatal detection of cystic fibrosis. Lancet 1984;i:959-60.

12 Ad Hoc Committee Task Force on Neonatal Screening, Cystic Fibrosis Foundation. Neonatal screening for cystic fibrosis: position paper. Pediatrics Foundation. Ne

13 Kerem B, Rommens JM, Buchanan JA, et al. Identification of the cystic fibrosis gene: genetic analysis. Science 1989;284: 1073-80.

14 Kerem B, Zielenski J, Markiewicz D, et al. Identification of mutations in regions corresponding to the two putative nucleotide (ATP) binding folds of the cystic fibrosis gene. Proc Natl Acad Sci 1990;87:8447-51.

15 Nelson PV, Carey WF, Morris CP, et al. The frequency of the common $\left(\Delta \mathrm{F}_{\mathrm{s} 0 \mathrm{~s}}\right)$ cystic fibrosis mutation in the Australian population. Med $\mathcal{J}$ Aust 1990;152:328.

16 Gibson LE, Cooke RE. A test for concentration of electrolytes in sweat in cystic fibrosis of the pancreas utilizing pilocarpine by iontophoresis. Pediatrics 1959;23:545-9.

17 Wilken B, Chalmers G. Reduced morbidity in patients with cystic fibrosis detected by neonatal screening. Lancet 1985;ii: 1319-21.

18 Dankert-Roelse JE, Meerman GJ, Martiin A, et al. Survival and clinical outcome in patients with cystic fibrosis, with or without neonatal screening. outcome in patients with cystic

19 Chatfield S, Owen G, Ryley HC, et al. Neonatal screening for cystic fibrosis in Wales and the West Midlands: clinical assessment after five years of

20 Wilken B, Brown ARD. Screening for cystic fibrosis in New South Wales, Australia: evaluation of the results of screening of 400000 babies. In: Therrell BL, ed. Advances in neonatal screening. Amsterdam: Elsevier Science Publishers, 1987:385-90.

21 Bowling FG, Bundesen PG, Brown ARD. A monoclonal antibody based trypsinogen enzyme-immunoassay screening test for cystic fibrosis. In: Therrell BL, ed. Advances in neonatal screening. Amsterdam: Elsevier Science Publishers, 1987:391-2.

22 Diamandis EP. Immunoassays with time-resolved fluorescence spectroscopy: principles and applications. Clin Biochem 1988:21:139-50.

23 Cutting GR, Kasch LM, Rosenstein BJ, et al. A cluster of cystic fibrosis mutations in the first nucleotide-binding fold of the cystic fibrosis conductance regulator protein. Nature 1990;346:366-9.

(Accepted 22 March 1991)
Department of Diabetes, University Hospital, Nottingham NG7 2UH Robert Tattersall, FRCP, professor

Robert Gregory, DM, registrar

Colin Selby, MRCP, registrar David Kerr, DM, registrar Simon Heller, DM, senior registrar

Correspondence and requests for reprints to: Professor Tattersall.

$B M \mathcal{F} 1991 ; 302: 1240-3$

\title{
Course of brittle diabetes: 12 year follow up
}

\author{
Robert Tattersall, Robert Gregory, Colin Selby, David Kerr, Simon Heller
}

Abstract

Objective-To determine the course of brittle diabetes.

Design-12 year follow up of patients identified in 1977-9 as having brittle diabetes; retrospective review of the case notes.

Setting-Nottingham health district.

Subjects-25 brittle diabetic patients were identified in 1979-9; 11 (five men) had three or more admissions with ketoacidosis between June 1977 and 1979 and 14 (eight men) had three or more attendances at the accident and emergency department with hypoglycaemia in 1978. Two controls from our diabetic register were matched to each patient for age, sex, and duration of diabetes.

Main outcome measures-Frequency of ketoacidosis and severe hypoglycaemia in the 12 years after ascertainment; diabetic control and complications in 1988-90; retrospective attribution of the cause of brittleness.

Results - Patients with recurrent ketoacidosis had had a median (range) of 28 (8-67) episodes. One man died of a cerebral tumour but five of the surviving nine patients had not been admitted in the past two years, although diabetic control remained poor (median haemoglobin $A_{1}$ concentration 14\%). Seven patients had pure hypoglycaemic brittleness, and five had also had eight or more admissions with ketoacidosis (mixed brittleness). Two died of uraemia within a year after ascertainment and two others in hypoglycaemic coma seven and 12 years later. Brittle diabetes was in most cases related to a specific situation, usually unhappiness at home or school.

Conclusions-Brittle diabetes is often episodic and almost always related to stressful life circum- stances. Once the underlying cause is removed it tends to improve. Recurrent hypoglycaemic brittleness of psychological origin has a poor prognosis.

\section{Introduction}

In 1977 one of us (RT) suggested a simple definition for a brittle diabetic patient: "the patient whose life is constantly disrupted by episodes of hyper- or hypoglycaemia, whatever their cause." Little is known about the course of brittle diabetes. Most studies have been cross sectional and concentrated on highly selected groups who have reached a specialist centre only because of the strain they place on hospital resources and family stability. We tried to clarify the course by an almost complete 12 year follow up of patients with recurrent ketoacidosis or severe hypoglycaemia from a defined population.

\section{Subjects and methods}

Nottingham has two general hospitals but only one accident and emergency department serving a population of 650000 . When this study started in 1977 the prevalence of diabetes treated with insulin in the catchment area was $3 \cdot 5 / 1000$ population. ${ }^{2}$ Most patients with insulin dependent diabetes in our catchment area attend a clinic at one of the general hospitals, and since 1978 their records have been kept on computer. ${ }^{3}$ Each patient has an annual review which includes height, weight, blood pressure, haemoglobin $A_{1}$ concentration (measured by electroendosmosis ${ }^{4}$ since 1982; normal range $4 \cdot 0-7 \cdot 5 \%$ of total haemoglobin), testing for proteinuria, ophthalmoscopy through dilated pupils, and neurological and vascular examination of the legs. Admissions to both hospitals are recorded by Hospital 